\title{
MICROPROPAGAÇÃO DO KIWI CV. HAYWARD ${ }^{1}$
}

\author{
FÁBIO EDUARDO SCALIZE²; FABÍOLA VITTI MÔRO³; CARLOS FERREIRA DAMIÃO FILHO ${ }^{4}$
}

\begin{abstract}
RESUMO - O presente trabalho teve como objetivo desenvolver um protocolo para a obtenção de mudas de kiwi (Actinidia chinensis Planch), cv. Hayward, por meio do cultivo in vitro de cotilédones. Utilizou-se o meio de MURASHIGE \& SKOOG (1962) - MS, suplementado com dois tipos de auxina (AIA e AIB) e uma citocinina (BAP). Foram verificados os efeitos de três doses de auxinas $\left(0,125 ; 0,250\right.$ e $\left.0,375 \mathrm{mg} . \mathrm{L}^{-1}\right)$, combinadas com três doses de citocinina $\left(0,5 ; 1,0 \mathrm{e} 1,5 \mathrm{mg} . \mathrm{L}^{-1}\right)$ na capacidade morfogênica dos explantes. Procedeu-se o estudo histológico dos órgãos das plântulas obtidas in vitro, e verificou-se, também, a capacidade de aclimatação das mudas ex vitro. A menor dose de AIB $\left(0,125 \mathrm{mg} . \mathrm{L}^{-1}\right)$, independentemente das doses de BAP, foi a mais eficaz na morfogênese dos explantes. Não foram verificadas alterações histológicas e anatômicas das plântulas obtidas in vitro. Aos três meses após o cultivo ex vitro dos explantes, verificou-se a sobrevivência de $88 \%$ das plantas transplantadas em condições de campo.
\end{abstract}

Termos para indexação: micropropagação, kiwi, cotilédones, aclimatação ex vitro.

\section{MICROPROPAGATION OF THE KIWI FRUIT 'HAYWARD'}

\begin{abstract}
The aim of this paper was to develop a protocol for plantlets production in kiwi fruit (Actinidia chinensis Planch) "Hayward" through in vitro cotyledons cultivation. For this purpose the Murashige \& Skoog (1962) medium was supplemented with two types of auxin (IAA and IBA) and also with a cytokinin (BAP). Effects over the morphogenic capacity of the explants were tested using three auxin $\left(0.125 ; 0.250\right.$ and $\left.0.375 \mathrm{mg} . \mathrm{L}^{-1}\right)$ and cytokinin $\left(0.5 ; 1.0\right.$ and $\left.1.5 \mathrm{mg} . \mathrm{L}^{-1}\right)$ concentrations. Studies in the obtained plantlets histology and acclimatization capacity were proceeded. It could be concluded that IBA at the lowest concentration $\left(0.125 \mathrm{mg}^{-\mathrm{L}^{-1}}\right) \mathrm{was}$ the most effective in explants morphogenesis, regardless of the BAP concentration. In vitro obtained plantlets did not present any anatomical nor histological alterations. Three months after transplanting it was observed that $88 \%$ of the plantlets had survived at field conditions.
\end{abstract}

Index terms: micropropagation, kiwi, cotyledons, ex vitro acclimatization.

\section{INTRODUÇÃO}

Originário do Sudeste da Ásia, o kiwi (Actinidia chinensis Planch) vegeta na forma de vigorosas plantas trepadeiras. Pertence à família Actinidiaceae e ao gênero Actinidia, o qual engloba mais de cem espécies (Hopping, 1986). Destas, poucas são cultivadas pelo efeito ornamental ou como frutífera, destacando-se, neste último aspecto, o kiwi.

A propagação da espécie, tanto por via assexuada quanto pela sexuada, é pouco estudada em nossas condições. O procedimento geralmente utilizado para a obtenção de mudas é a estaquia ou a enxertia, sendo que ambos os métodos produzem mudas de qualidade e muito produtivas, desde que sejam selecionadas as plantas matrizes. Há, também, outros métodos de propagação do kiwi, tais como a alporquia e a utilização de ramos adventícios. A propagação gâmica é evitada devido à dormência das sementes e, pela dioecia que a espécie apresenta, dificulta-se o estabelecimento de cultivos comerciais, os quais, preferencialmente, devem ser constituídos por maior número de plantas pistiladas e produtivas.
A literatura a respeito da micropropagação do kiwi é bastante extensa e vários trabalhos (Halperin, 1966; Jordan et al.,1986; Leva \& Magrini; 1986; Canhoto \& Cruz, 1987; Monette, 1987; Pais \& Oliveira, 1987; Wan et al., 1987; Leva \& Bertocci, 1988; Revilla \& Power, 1988; Muleo \& Morini, 1989; Radice et al., 1989; Sammarcelli \& Legave, 1990; Xiao et al., 1991; Fortes et al., 1995) têm sido desenvolvidos.

A análise crítica da literatura consultada, referente à obtenção de propágulos de kiwi por meio de cultura de tecidos, permite inferir que, apesar dos diferentes resultados experimentais, as seguintes linhas gerais de procedimentos podem ser seguidas, objetivando-se a micropropagação da espécie: a) o processo de obtenção de plântulas inicia-se pela formação de calo; b) os calos podem ser formados a partir de diversos tipos de explantes (folhas jovens, segmentos de caule, nós caulinares, cotilédones); c) as auxinas mais comumente utilizadas (ANA ácido naftalenoacético, AIA - ácido indolacético, AIB - ácido indolbutírico e 2,4-D - ácido 2,4 diclorofenoxiacético) são efetivas na indução de calos; d) a regeneração dos calos formados é possível, sendo a BAP (benzilaminopurina) e a ZEA (zeatina)

1 (Trabalho 226/2000). Recebido: 13/10/2000. Aceito para publicação: 21/09/2001.

2 Bolsista da FAPESP. FCAV/UNESP - Dept Biologia Aplicada à Agropecuária - Rodovia Paulo D. Castellane km 5; Cep 14884900,Jaboticabal,SP,Brasil.

3 Prof ${ }^{\mathrm{a}}$ Assistente Dra. FCAV/UNESP - Dept Biologia Aplicada à Agropecuária - Rodovia Paulo D. Castellane km 5; Cep 14884900,Jaboticabal,SP,Brasil. mailto fabiola@fcav.unesp.br.

4 Prof. Assistente Dr. FCAV/UNESP - Dept Biologia Aplicada à Agropecuária - Rodovia Paulo D. Castellane km 5; Cep 14884-900,Jaboticabal,SP,Brasil. mailto damiao@fcav.unesp.br. 
indutoras de brotações adventícias; e e) o enraizamento pode ser efetuado por meio de subcultivos em meios contendo baixas concentrações de auxinas ou por imersão das brotações em soluções mais concentradas das mesmas. Ainda, na literatura consultada, não foram levantados trabalhos com a micropropagação da espécie a partir do cultivo de cotilédones, nem informações sobre a histologia de plântulas formadas in vitro.

A fase de aclimatação ex vitro do kiwi é bastante delicada, sendo obtida, segundo Sammarcelli \& Legale (1990), sob nebulização, em casa de vegetação e em substrato aerado. Com a associação dessas técnicas, os autores estimaram a obtenção de três a quatro plantas aclimatadas por explante, obtido em cultura, em menos de quatro meses.

O objetivo do presente trabalho foi a identificação de procedimentos para a micropropagação do kiwi, por meio do cultivo in vitro de cotilédones, o de efetuar estudos histológicos nas plântulas produzidas in vitro, e o estudo da efetividade de processos para a aclimatação dos propágulos obtidos.

\section{MATERIAL E MÉTODOS}

O experimento foi inicialmente conduzido, durante a fase de micropropagação, no Laboratório de Cultura de Tecidos de Plantas do Departamento de Biologia Aplicada à Agropecuária, da Faculdade de Ciências Agrárias e Veterinárias (FCAV), UNESP, em Jaboticabal-SP.

A aclimatação das mudas obtidas in vitro foi realizada no "Ripado da Fruticultura", localizado na "Fazenda de Ensino e Pesquisa" da FCAV-Jaboticabal. A instalação, em condições de campo, das mudas aclimatadas, foi realizada em área experimental da "Fazenda de Ensino e Pesquisa".

A cultivar de kiwi estudada foi a 'Hayward', devido sua adaptação ao clima e por ser a que permite os mais longos períodos de armazenamento dos frutos.

Para a quebra de dormência das sementes de kiwi, estas foram imersas em solução de ácido giberélico $\left(\mathrm{GA}_{3}\right)$, grau III, na concentração de $500 \mathrm{mg}$. $\mathrm{L}^{-1}$ durante seis horas, de acordo com metodologia indicada por Carvalho \& Damião Filho (1993).

Sob condições assépticas, as sementes foram esterilizadas superficialmente e semeadas em tubos de cultura, com capacidade volumétrica de $125 \mathrm{ml}$, contendo, cada tubo, $10 \mathrm{ml}$ da solução salina de Murashige \& Skkog (1962) - MS, diluída na metade da concentração original $\left(\mathrm{MS}_{1 / 2}\right)$, sendo o pH ajustado para 5,7 e o meio semi-solidificado com $0,6 \%$ de ágar bacteriológico, autoclavado a $120^{\circ} \mathrm{C}$ e 1 atm de pressão, durante vinte minutos.

Os recipientes contendo as sementes foram colocados sob luz difusa, no interior do laboratório, permanecendo nestas condições durante trinta dias. Após este período, as plântulas obtidas, com dois cotilédones totalmente expandidos, foram utilizadas como fonte de explantes.

As plântulas obtidas in vitro foram conduzidas para câmara asséptica e, com auxílio de instrumental esterilizado, foram retiradas dos tubos de culturas, colocadas sobre placas de vidro esterilizadas, sendo ambos os cotilédones excisados de cada uma das plântulas matrizes. Os cotilédones, juntamente com os respectivos pecíolos, serviram como explantes para o processo de micropropagação.
Num primeiro cultivo, os cotilédones foram transferidos para o meio básico MS, contendo três diferentes doses de duas auxinas: $\mathrm{MS}_{\text {aia }}$, suplementado com ácido indolacético (AIA) nas concentrações de 0,$125 ; 0,250$ e $0,375 \mathrm{mg} . \mathrm{L}^{-1}$, e $\mathrm{MS}_{\text {aib }}$, suplementado com ácido indolbutírico (AIB) nas concentrações de 0,$125 ; 0,250$ e $0,375 \mathrm{mg}$. $\mathrm{L}^{-1}$. Para cada tratamento, foram feitas 75 repetições (tubos de cultura), contendo um cotilédone por tubo. Os explantes permaneceram nestes meios durante 35 dias. Após esse período, os explantes oriundos de cada um dos tratamentos anteriormente descritos foram transferidos para o meio básico, contendo benzilaminopurina, $\mathrm{MS}_{\mathrm{ba}}$, nas concentrações de 0,$5 ; 1,0$ e 1,5 mg. $\mathrm{L}^{-1}$. Para cada tratamento deste subcultivo, foram feitas 25 repetições (75 repetições originais distribuídas aleatoriamente em meio $\mathrm{MS}_{\mathrm{ba}}$, com três concentrações do regulador de crescimento). Os explantes permaneceram nos meios de subcultivo durante 35 dias. A seguir, foram transferidos para o meio básico MS, sem a adição de reguladores de crescimento, permanecendo em tais condições durante 40 dias. Ao término deste período experimental, as plântulas obtidas foram submetidas a avaliações morfológicas, e os dados foram analisados estatisticamente.

O delineamento experimental adotado foi o inteiramente casualizado, com os tratamentos dispostos no esquema fatorial $2 \times 3 \times 3$, com dois tipos de auxinas em três doses, combinadas com três doses de benzilaminopurina, com 25 repetições cada tratamento.

Dez plantas representativas de cada tratamento foram retiradas dos recipientes de vidro e analisadas quanto ao peso de matéria fresca e ao peso de matéria seca da plântula, número total de raízes emitidas, número de brotações (referindo-se à quantidade de partes aéreas formadas), altura da parte aérea e número de folhas.

Para a realização dos estudos histológicos, testaram-se dois métodos de emblocamento do material, ou seja, "Método da Historresina-2-Hidroxietil Metacrilato" e o método descrito por Constabel, citado por Gamborg \& Wetter (1975). Para ambos os métodos, os fragmentos foram conservados em solução fixadora de "Bouin-Hollande" por um período mínimo de 24 horas, para fixação. Decorrido o tempo de fixação, as amostras foram submetidas à seqüência de desidratação alcoólica, descrita por cada autor. As lâminas histológicas, obtidas em ambos os métodos, foram analisadas e documentadas com o auxílio de fotomicroscópio ótico, marca Docuval. A análise de ambas as superfícies foliares foi feita por meio de impressão "em cola" (adesivo à base de éster de cianoacrilato), em lâmina de vidro.

A fase de aclimatação consistiu da retirada das plantas provenientes do cultivo in vitro, seguindo-se de imersão em água corrente para a remoção total do meio de cultura e transferência das mesmas para copos plásticos, perfurados, contendo vermiculita como substrato. Tais copos foram acondicionados em câmara de nebulização intermitente, em ripado com $50 \%$ de incidência solar onde a umidade relativa do ar foi mantida em, aproximadamente, $90 \%$.

Decorridos dez dias, as plantas foram repicadas para substrato constituído por terra, areia e esterco de curral curtido na proporção de $1: 1: 1$, contidos por sacos pásticos de polietileno preto. Após a transferência, as plantas foram retornadas para a câmara de nebulização por, aproximadamente, dez dias. Em seguida, as plantas foram transferidas para condição de ripado, 
com irrigação diária por microaspersão, pela manhã e à tarde.

Aos seis meses após o início do processo de aclimatação, as mudas foram transplantadas para o campo, num total de dezessete plantas, em covas individuais, no sistema de espaldeira. Procedeu-se irrigação diária na primeira semana, seguindo-se irrigações em dias alternados, até a verificação do "pegamento" das mudas.

\section{RESULTADOS E DISCUSSÃO}

As sementes de kiwi são pequenas, e a estimativa do desvio-padrão da média dos pesos das amostras, com valor próximo a zero $(0,00128)$, evidencia que tais sementes são estenospérmicas, ou seja, apresentam pequena variação entre si. Um grama de sementes contém, aproximadamente, 740 unidades.

A primeira manifestação morfológica dos explantes ocorreu após 35 dias da inoculação, constituindo na emissão de raízes, geralmente na base dos pecíolos dos cotilédones cultivados, independentemente do meio de cultura e tratamentos utilizados. Constatou-se, também, intensa formação de pêlos radiculares nas raízes oriundas dos explantes (Figura 1).

Concomitantemente, ou com pequeno intervalo de tempo após a emissão de primórdios radiculares, observou-se a emissão de primórdios foliares, também na porção terminal (próxima ao hipocótilo da plântula) do pecíolo do cotilédone de kiwi excisado.

Aos 110 dias após a inoculação dos explantes, por ocasião do início do processo de aclimatação, as plântulas produzidas in vitro apresentavam-se desenvolvidas, com uma média de 10 folhas, aproximadamente (Figura 2).

Apesar de todos os tratamentos serem eficazes para a morfogênese do kiwi, o número de raízes e o peso de matéria seca de plântulas foram as duas variáveis que diferiram significativamente das demais, em função do tipo de auxina utilizada, conforme pode ser observado na Tabela 1.

Com relação às demais variáveis, nota-se que, pela análise dos dados, há indicação da menor dose de AIB $\left(0,125 \mathrm{mg} . \mathrm{L}^{-1}\right)$, como sendo a que melhores respostas determinou, indicando não haver diferenças nas doses de AIB utilizadas, mas, sim, nos efeitos das auxinas e das doses empregadas.

Os resultados anteriormente apresentados, referentes aos efeitos dos reguladores de crescimento do grupo das auxinas, o AIB e o AIA, sobre os explantes cotiledonares do kiwi e a formação de primórdios radiculares, não diferem dos amplamente citados na literatura da cultura de tecidos de plantas. Flick et al. (1983) afirmam que as auxinas, isoladamente ou em combinação com uma baixa concentração de citocinina, são importantes na indução de primórdios radiculares e George \& Sherrington (1984) corroboram o fato, apontando que a rizogênese é decorrente do tratamento com altas concentrações de auxina em relação à de citocinina, em cultivos in vitro.

Apesar de não ocorrerem diferenças significativas quanto às variáveis "número de brotações", "altura da parte aérea" e "número de folhas", os resultados indicam uma tendência de que plantas cultivadas em meio de cultura suplementado com AIB, independentemente das doses utilizadas, são mais compactas (de menor altura média), apresentando, porém, maior número médio de brotações e de folhas.
Os tecidos foliares do kiwi (Figura 3 - A), em estágio inicial de crescimento in vitro, apresentam-se diferenciados, acompanhando os padrões morfológicos típicos de uma folha de dicotiledônea. A epiderme superior é composta por células epidérmicas relativamente de maior calibre que as da epiderme inferior, com parede periclinal externa mais espessa que a interna, sendo ambas com formato tabular. O mesófilo é composto por células parenquimáticas irregulares, com braços, havendo presença de amplos espaços intercelulares. A primeira camada de células, abaixo da epiderme superior, apresenta-se formada por células parenquimáticas mais adensadas (próximas umas das outras), assemelhando-se a um parênquima paliçádico em formação, ainda não completamente diferenciado. Na região da nervura central, observa-se que o tecido parenquimático, acima da epiderme inferior, é formado por células com poucos espaços intercelulares (mais compactas), de calibre maior do que as voltadas para a epiderme superior. $O$ feixe vascular central apresenta-se bem formado, diferenciando-se tecido xilemático voltado para a epiderme superior e floemático, para a inferior. No xilema, na região protoxilemática, observam-se lacunas, originadas por esse tipo de desenvolvimento celular; também, são observados elementos de vaso, com paredes secundárias em início de formação. Ressalta-se a existência de uma bainha de células, rodeando o tecido vascular. Verificou-se a existência de estômatos (Figura 3 - B) com formato reniforme e células epidérmicas fundamentais, com formato irregular, compondo a epiderme inferior. Não se observou a presença de tricomas, os quais, entretanto, se encontravam presentes em ambas as epidermes, antes do preparo das lâminas histológicas. O desaparecimento destes é atribuído ao método empregado para o preparo das lâminas, ou seja, impressão com adesivo (éster de cianoacrilato). Os estômatos, em sua maioria, apresentam-se com os poros estomáticos fechados, indicando que as condições de cultivo in vitro não influíram no mecanismo de abertura e fechamento dos poros estomáticos.

A raiz, vista em corte transversal na Figura 4, mostra-se como órgão com histologia típica de uma raiz-"padrão" de dicotiledônea. O revestimento da raiz é constituído por uma epiderme, na qual se encontram células epidérmicas com expansões tubulares, os pêlos epidérmicos. Abaixo da camada celular epidérmica, há uma exoderme bem evidente, com espessamento na parede periclinal externa. $O$ restante do córtex segue-se à exoderme, sendo constituído por células parenquimáticas, com pequenos espaços intercelulares, e nas quais não se observa acúmulo de organelas citoplasmáticas, com a mesma intensidade do que nas folhas. Há presença de alguns idioblastos, sendo a substância segregada nestes provavelmente (pela coloração apresentada) de composição tanínica. A endoderme, última camada celular do córtex, está presente e bem diferenciada. O cilindro central é formado por um periciclo e quatro pólos de xilema, que se alternam com tecido floemático, em configuração tetrarca.

A Figura 5 - A, que detalha a porção mais superficial do caule, mostra que esse órgão é revestido por uma epiderme formada por células compactas, sem espaços intercelulares. Logo abaixo da epiderme, ainda em formação e, portanto, não completamente diferenciada, verifica-se uma exoderme, composta por uma a duas camadas celulares. $O$ córtex é formado por células parenquimáticas de formato irregular, densamente arranjadas, com 
pequenos espaços intercelulares entre si, mostrando acúmulo, em seus citoplasmas, de organelas que, em alguns casos, se depositam próximas das paredes celulares e, em outros, espalhamse pelo interior do protoplasma.

A Figura5 - B revela, em detalhes, o cilindro vascular. Compondo este, encontram-se células xilemáticas mais especializadas e conspícuas, com espessa parede secundária e coloração vermelha, resultado da reação dos componentes dessa parede celular com safranina. O floema apresenta-se com células menores, em posição externa ao xilema, e há indicações, no momento da amostragem, de que estava ocorrendo intensa divisão celular.

De maneira geral, pode-se afirmar que, em virtude dos aspectos morfológicos e anatômicos das plântulas de kiwi, obtidas in vitro, não diferirem dos padrões regulares de crescimento de uma plântula de dicotiledônea, o sistema de cultivo não ocasionou mutações - ao menos expressivas - nas plântulas de kiwi obtidas por esse processo.

Aproximadamente 12 meses após o início do experimento, ou seja, desde a inoculação dos explantes (folhas cotiledonares) em meio de cultura, as plantas foram transplantadas para condições de campo. Houve em torno de $88 \%$ de sobrevivência das plantas transplantadas, ou seja, das 17 mudas, apenas duas não sobreviveram às condições de campo, evidenciando que os procedimentos usados na aclimatação das mesmas foram efetivos.

\section{CONCLUSÕES}

De acordo com os resultados obtidos, dentro das

TABELA 1 - Resultados da análise de variância do peso de matéria fresca (g); de matéria seca (g); do número de raízes e de brotações; da altura da parte aérea $(\mathrm{cm})$ e do número de folhas de plântulas de kiwi, submetidas aos tratamentos com dois tipos de auxinas (A) (AIA e AIB), combinadas com três doses de BAP (B) $\left(0,5 ; 1,0\right.$ e 1,5 mg.L - $\left.^{-1}\right)$ e três doses de auxinas (C) $(0,125$; 0,250 e 0,375 mg. $\mathrm{L}^{-1}$ ) e as interação entre AxB; AxC, BxC e AxBxC.

\begin{tabular}{|c|c|c|c|c|c|c|}
\hline & PESO DE & PESO DE & NÚMERO & NÚMERO & ALTURA DA & NÚMERO \\
\hline \multirow[t]{2}{*}{ AUXINA (A) } & MATÉRIA & MATÉRIA & DE RAÍZES & DE BROTAÇÕES & PARTE & DE FOLHAS \\
\hline & $\operatorname{FRESCA}(g)$ & $\operatorname{SECA}(g)$ & & \multicolumn{3}{|c|}{ AÉREA(cm) } \\
\hline AIA & $0,0888^{\mathrm{a}}$ & $0,0093 b$ & $0,7129 b$ & $1,4440 \mathrm{a}$ & $0,8686 \mathrm{a}$ & $3,7778^{\mathrm{a}}$ \\
\hline AIB & $0,1628^{\mathrm{a}}$ & $0,0180 \mathrm{a}$ & $0,8069 \mathrm{a}$ & $1,5058 \mathrm{a}$ & $0,6869 \mathrm{a}$ & $4,6333^{\mathrm{a}}$ \\
\hline TESTE F & $3,52 \mathrm{NS}$ & $10,1089 * *$ & $12,2153 * *$ & $1,1704 \mathrm{NS}$ & $1,4774 \mathrm{NS}$ & $1,191 \mathrm{NS}$ \\
\hline $\mathrm{dms}(5 \%)$ & 0,0778 & 0,0054 & 0,0531 & 0,1201 & 0,2951 & 1,5476 \\
\hline \multirow{3}{*}{ DOSES auxinas (B) } & PESO DE & PESO DE & NÚMERO & NÚMERO & ALTURA DA & NÚMERO \\
\hline & MATÉRIA & MATÉRIA & DE RAÍZES & DE BROTAÇÕES & PARTE & DE FOLHAS \\
\hline & $\operatorname{FRESCA}(\mathrm{g})$ & $\operatorname{SECA}(g)$ & & \multicolumn{3}{|c|}{ AÉREA(cm) } \\
\hline $0,125{\mathrm{mg}, \mathrm{L}^{-1}}^{-1}$ & $0,1569 \mathrm{a}$ & $0,0165 \mathrm{a}$ & $0,8223 \mathrm{a}$ & $1,4979 \mathrm{ab}$ & $0,7132 \mathrm{ab}$ & $4,3667 \mathrm{ab}$ \\
\hline $0,250 \mathrm{mg}, \mathrm{L}^{-1}$ & $0,1565 \mathrm{a}$ & $0,0170 \mathrm{a}$ & $0,7416 b$ & $1,5632 \mathrm{a}$ & $1,0683 \mathrm{a}$ & $5,4833^{\mathrm{a}}$ \\
\hline $0,375 \mathrm{mg}, \mathrm{L}^{-1}$ & $0,0640 \mathrm{a}$ & $0,0076 \mathrm{~b}$ & $0,7157 b$ & $1,3695 b$ & $0,5517 \mathrm{~b}$ & $2,7667 b$ \\
\hline TESTE & $2,4564 \mathrm{NS}$ & $4,9556 * *$ & $5,6899 * *$ & $3,4953 *$ & $4,1699 *$ & $4,0464 *$ \\
\hline $\operatorname{Dms}(5 \%)$ & 0,1143 & 0,0079 & 0,0780 & 0,1764 & 0,4332 & 2,2720 \\
\hline DOSES (C) & PESO DE & PESO DE & NÚMERO & NÚMERO & ALTURA DA & NÚMERO \\
\hline \multirow[t]{2}{*}{ Citocinina BAP } & MATÉRIA & MATÉRIA & DE RAÍZES & DE BROTAÇÕES & PARTE & DE FOLHAS \\
\hline & $\operatorname{FRESCA}(g)$ & $\operatorname{SECA}(g)$ & & \multicolumn{3}{|c|}{ AÉREA(cm) } \\
\hline $0,5 \mathrm{mg}, \mathrm{L}^{-1}$ & $0,1127 \mathrm{a}$ & $0,0136 \mathrm{a}$ & $0,7652 a$ & $1,4935 \mathrm{a}$ & $0,8462 \mathrm{a}$ & $4,7167^{\mathrm{a}}$ \\
\hline $1,0 \mathrm{mg}, \mathrm{L}^{-1}$ & $0,1307 \mathrm{a}$ & $0,0152 \mathrm{a}$ & $0,7501 \mathrm{a}$ & $1,5518 \mathrm{a}$ & $0,8653 \mathrm{a}$ & $4,3000^{\mathrm{a}}$ \\
\hline $1,5 \mathrm{mg}, \mathrm{L}^{-1}$ & $0,1340 \mathrm{a}$ & $0,0122 \mathrm{a}$ & $0,7244 \mathrm{a}$ & $1,3854 \mathrm{a}$ & $0,6217 \mathrm{a}$ & $3,6000^{\mathrm{a}}$ \\
\hline TESTE F & $0,1123 \mathrm{NS}$ & $0,4109 \mathrm{NS}$ & $2,0295 \mathrm{NS}$ & $2,5677 \mathrm{NS}$ & $1,0957 \mathrm{NS}$ & $0,691 \mathrm{NS}$ \\
\hline Dms $(5 \%)$ & 0,1143 & 0,0079 & 0,0780 & 0,1764 & 0,4332 & 2,2720 \\
\hline \multirow[t]{3}{*}{ INTERAÇÕES } & PESO DE & PESO DE & NÚMERO & NÚMERO & ALTURA DA & NÚMERO \\
\hline & MATÉRIA & MATÉRIA & DE RAÍZES & DE BROTAÇÕES & PARTE & DE FOLHAS \\
\hline & $\operatorname{FRESCA}(\mathrm{g})$ & $\operatorname{SECA}(g)$ & & \multicolumn{3}{|c|}{ AÉREA(cm) } \\
\hline $\mathrm{AxB}$ & $0,2418 \mathrm{NS}$ & $0,0294 \mathrm{NS}$ & $2,0442 \mathrm{NS}$ & $2,3593 \mathrm{NS}$ & $0,3196 \mathrm{NS}$ & $0,3800 \mathrm{NS}$ \\
\hline $\mathrm{AxC}$ & $5,0626 * *$ & $9,5641 * *$ & $7,2748 * *$ & $4,4218^{*}$ & $6,3118 * *$ & $4,6769 *$ \\
\hline $\mathrm{BxC}$ & $0,3762 \mathrm{NS}$ & $0,2342 \mathrm{NS}$ & $1,0328 \mathrm{NS}$ & $0,9384 \mathrm{NS}$ & $0,2988 \mathrm{NS}$ & $1,8961 \mathrm{NS}$ \\
\hline $\mathrm{AxBxC}$ & $0,2309 \mathrm{NS}$ & $0,0901 \mathrm{NS}$ & $1,0255 \mathrm{NS}$ & $0,4434 \mathrm{NS}$ & $0,4959 \mathrm{NS}$ & $0,382 \mathrm{NS}$ \\
\hline
\end{tabular}

NS - não significativo ao nível de $1 \%$ de probabilidade, pelo teste de Tukey

* - significativo ao nível de $5 \%$ de probabilidade, pelo teste de Tukey

** - significativo ao nível de $1 \%$ de probabilidade, pelo teste de Tukey

dms - desvio mínimo significativo, ao nível de 5\% de probabilidade. 


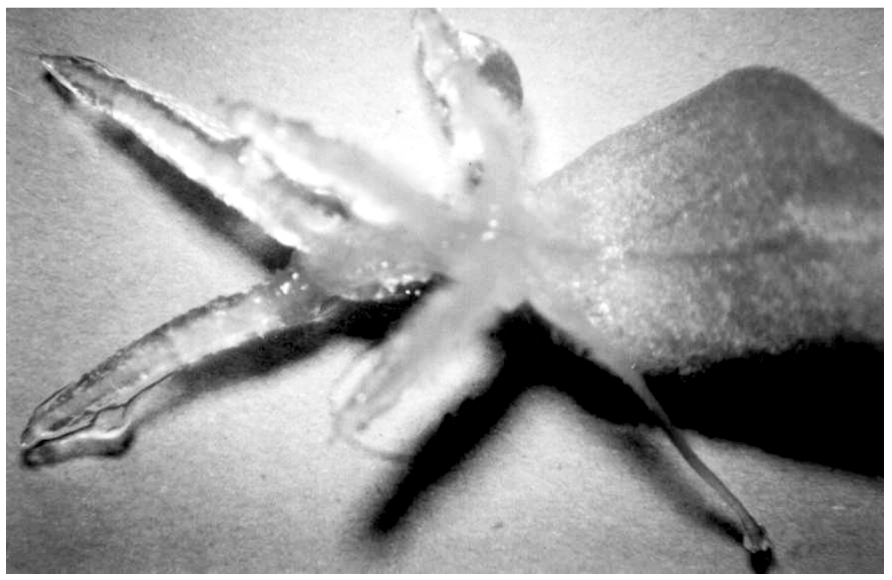

FIGURA 1 - Explante cotiledonar do kiwi, aos 35 dias após inoculação, evidenciando a emissão de primórdios radiculares, na base do pecíolo. Jaboticabal-SP, 1999.

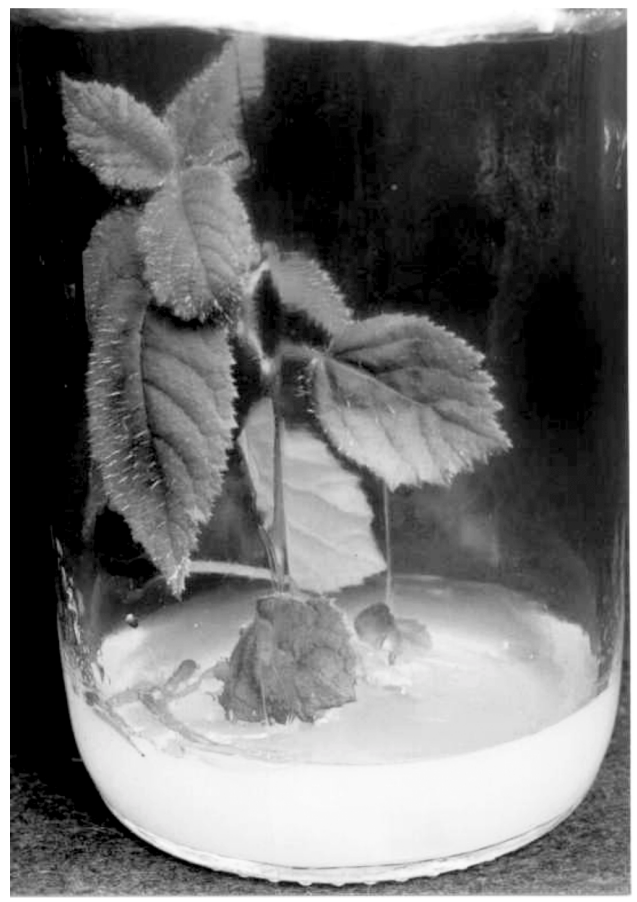

FIGURA 2 - Plântula de kiwi, aos 110 dias após a inoculação, apta para o cultivo ex vitro. Jaboticabal-SP, 1999.
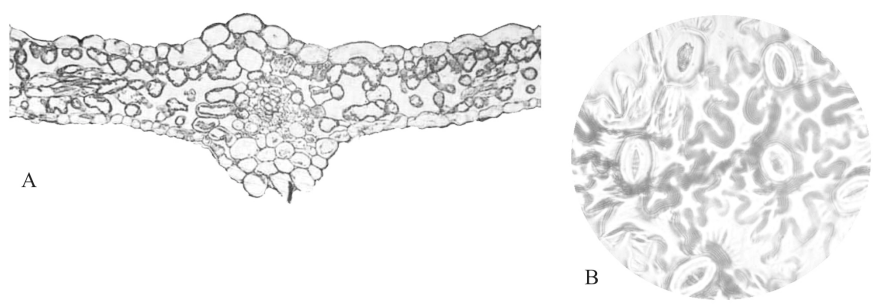

FIGURA 3 - A - Corte transversal na região mediana do limbo foliar do kiwi, evidenciando-se a epiderme superior, a epiderme inferior, o mesófilo e o feixe vascular da nervura mediana; B - impressão da epiderme inferior de folha do kiwi, revelando configuração normal dos estômatos e células epidérmicas fundamentais. Jaboticabal-SP, 1999.

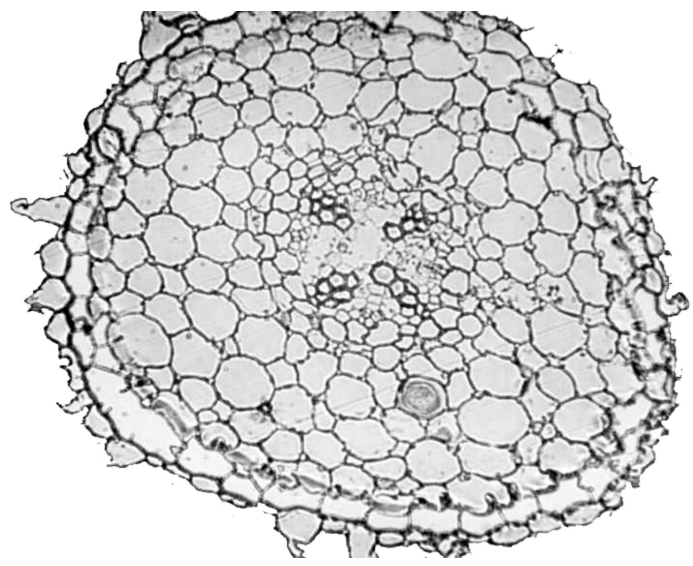

FIGURA 4 - Corte transversal na raiz do kiwi, de plântula obtida in vitro, evidenciando as células epidérmicas com expansões tubulares (pêlos radiculares), a região cortical e o cilindro central. Jaboticabal-SP, 1999.
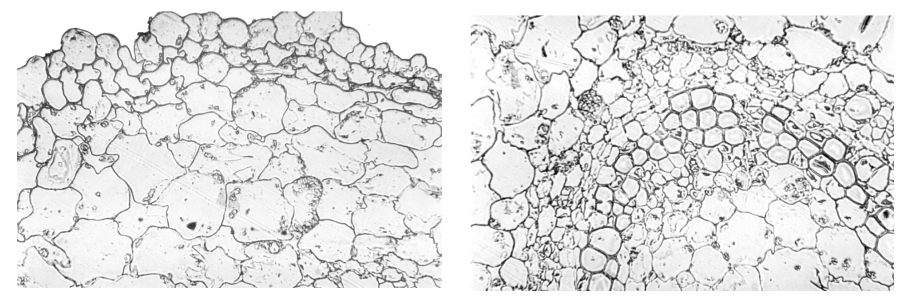

FIGURA 5 - Corte transversal no caule do kiwi, de plântula obtida in vitro. A - região periférica do caule, evidenciando a camada epidérmica, a exoderme e parte do córtex; $\mathrm{B}$ - córtex do caule do kiwi, evidenciando o cilindro vascular.

presentes condições experimentais, pode-se concluir que:

1) O kiwi é uma espécie com elevado potencial morfogenético aos meios de cultura e os reguladores de crescimento utilizados, e ambas as auxinas testadas, AIA e AIB, foram eficazes na multiplicação in vitro do kiwi, cv. Hayward.

2) A interação entre auxinas e a citocinina BAP, nas doses experimentais testadas, não ocasionaram diferenças significativas nas características avaliadas.

3) O estudo da histologia das partes constituintes das plântulas de kiwi obtidas in vitro demonstrou não ter ocorrido alterações morfológicas, quando da comparação das mesmas com tecidos de dicotiledôneas obtidas por propagação gâmica.

4) De maneira geral, verificou-se que os melhores resultados para a obtenção de mudas de kiwi, a partir de folhas cotiledonares, com a utilização de cultura de tecidos, foram por meio da suplementação do meio de cultura MS com o ácido indolbutírico, na dose de $0,125 \mathrm{mgL}^{-1}$.

5) Mudas produzidas in vitro e transplantadas para campo, apresentaram uma alta taxa de sobrevivência.

\section{REFERÊNCIAS BIBLIOGRÁFICAS}

CANHOTO, J.M.; CRUZ, G.S. In vitro multiplication of Actinidia chinensis Planch by culture of young leaves. Boletim da Sociedade Broteriana, Coimbra, v.2, n.60, p.239-52,1987. 
CARVALHO, G.L.; DAMIÃO FILHO, C.F. Germinação do kiwi (Actinidia deliciosa) in vitro. In: CONGRESSO DE INICIAÇÃO CIENTÍFICA, 5., 1993, Bauru. Anais... p.185-6.

EVANS, D.A.; SHARP, W.R.; FLINK, C.E. Growth and behavoir of cell cultures: embriogenesis. In: THORPE, T.A. (Ed.), Plant tissue culture: methods and applications in agriculture. New York: Academic Press, 1981. p. 45-113.

FORTES, G.R.L; FIGUEIREDO, S.L.B.; NACHTIGAL, J.C., ZECCA, A.G.D. Influência da Benzilaminopurina (BAP) na multiplicação in vitro de kiwi (Actinidia deliciosa). Ciência Rural, v.25, n.1, p.23-6, 1995.

FLICK, C.E., EVANS, D.A., SHARP, W.R. Techniques for propagation and breeding: Organogenesis. In: . HANDBOOK of plant cell culture. 1983. v.1, cap.2, p.13-68.

GAMBORG, O.L.; WETTER, L.R. Plant tissue culture methods. local: Editora 1975. p.102.

GEORGE, E.F.; SHERRINGTON, P.D. Plant propagation by tissue culture. Eversley: Exegetics, 1984. p.9.

HALPERIN, W. Aternative morphogenetic events in cell suspensions. American Journal of Botany, Columbus, v.53, p.443-53, 1966.

HOPPING, M.E. Kiwifruit. In: MONSELISE, S.P.(Ed.). Handbook of fruit sett and development. Boca Raton: CRC Press, 1986. p.217-32.

JORDAN, M.; MEDINA, C.; MUJICA, A.M., Micropropagation of kiwi (Actinidia chinensis Planch): Histochemical studies of in vitro induced morphogenesis. Ciencial Investigación Agraria, Santiago, v.13, p.207-12, 1986.

LEVA, A.R.; BERTOCCI, F. The effect of sorbitol and mannitol on the morphogenesis of Actinidia deliciosa Liang or Ferguson, callus. Acta Horticulturae, Wageningen, n.227, p.447-9, 1988.

LEVA, A.R.; MAGRINI, P. Callus growth factors and shoot prodution in Actinidia chinensis $\mathrm{Pl}$. and Actinidia arguta Pl., Rivista della Ortofloro Fruticoltura Italiana, v.70, p.46-56, 1986.

MONETTE, P.L. Organogenesis and plantlet regeneration following in vitro cold storage of kiwifruit shoot tip cultures. Journal of Horticultural Science, Ashford, v.31, p.101-6, 1987.

MULEO, R.; MORINI, S. Effect of light quality on regeneration from callus of Actinidia deliciosa. Acta Horticulturae, Wageningen, n.280, p.155-8,1989.

MURASHIGE, T.; SKOOG, F. A revised medium for rapid growth and bioassays with Tobbaco tissue cultures. Physiology Plantarum, Copenhagen, v.15, p.473-97, 1962.

PAIS, M.S.S.; OLIVEIRA, M.M. Use of petiole segments of Actinidia chinensis (kiwi) for plant differentiation and production of fieble calli for protoplast isolation. Acta Horticulturae, Wageningen, n.212, p.687-90, 1987.

RADICE, S.; CASO, O.H.; REYNOSO, H.D. Comportamiento en vivero de plantas micropropagadas de kiwi (Actinidia chinensis Planch). In: REUNIÓN DE LA SOCIEDAD LATINOAMERICANA DE FISIOLOGIA VEGETAL, 10., 1989., Puerto Iguazú. Anais... p. 211.

REVILLA, M.A., POWER, J.B. Morphogenetic potential of longterm callus cultures of Actinidia deliciosa. Journal Horticultural Science, Ashford, v.63, n.3, p.541-5, 1988.

SAMMARCELLI, F., LEGAVE, J.M. MULTIPLICATION IN VITRO PAR NÉOFORMATION CHEZ L' ACTINIDIA DELICIOSa, cultivar Hayward. Fruits, Paris, v.45, n.4, p.393-401, 1990.

XIAO, X..G., HIRSCH, A.M., FORTUNE, D. Regeneration of kiwi (Actinidia deliciosa cv.Hayward) from young leaves. Fruits, Paris, v.46, n.1, p.57-66, 1991.

WAN, M., ZHANG, X.L., CUN, S.X. First report on rapid propagation technique by stem tissue culture of kiwifruit. Yunnan Agricultural Science and Technology, n.4, p.20-3, 1987. 